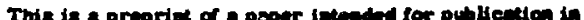

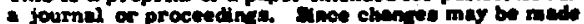

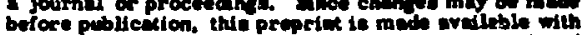
the und retending thet is wil oot be ciled or reproduced withow the perminedion of the enthor.
UCRL - 72507

PREPRINT

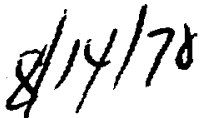

$$
\cos \cdot 70100 /-3
$$

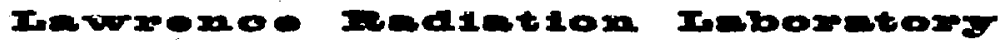

\title{
UHIVERSITY OF GALIFOAHIA
}

\section{LIVERMORE}

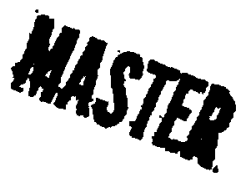

\section{DEFORMATION OF CRYSTALS OF ALPHA PLUTONIUN N COMPRESSION}

\author{
Robert G. Liptai \\ Robert J. Friddle
}

June 11,1970
THA DocUMENT Covifinnd As UMCLASUFISD

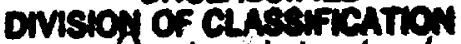

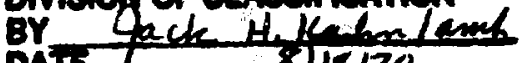
DNIET 315170

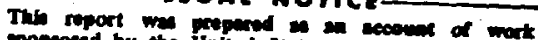

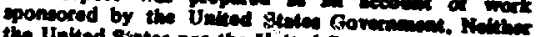
the United States nor the Uniwed staw Atomic Lerty

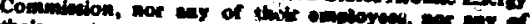

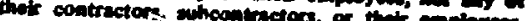

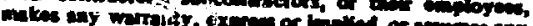

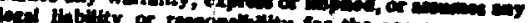

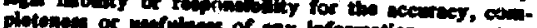

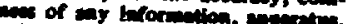

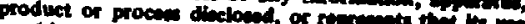

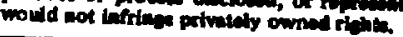

This paper was prepared for presentation to the 4th International Conference on Plutorium and Other Actinides 


\title{
DFFORMATION OF CRYSTALS OF ALPHA PLUTONIJM
}

\author{
IN COMPRESSION*
}

\author{
Robert G. Liptai \\ Lawrence Radiation Laboratory \\ University of Califormia \\ Livermore, Californin 94550 \\ and \\ Robert J. Friddle \\ Argonne National Laboratory \\ Argonne, yllinois 60439
}

The crystal structure of alpha plutonium is complex and of low symmetry (monoclinic, space group $\mathrm{P} 2_{1} / \mathrm{m}$ ). Several slip planes have been suggested, namely, (020) and (001). Investigators at Los Alamos have reported that slip planes near (114), (213), and (323) are operative at room temperature in small-grained specimens. In the present study, large crystals of alpha plutonium (to $2 \times 2 \times 5 \mathrm{~mm}$ ) were prepared by high-pressure techniques. The results of a study to identify the deformation mechanisms and the stress-strain characteristics of alpha plutonium, at room temperature are reported. All tests were compressive. The slip planes were identified by two-surface analysis.

Slip was the dominant deformation mechanism; however, some evidence suggests that twinning deformations were present. Results have shown that several slip plants are operative, apparently depending on the crystallographic direction of strain. Although most samples revealed only one slip plane, three planes were noted in one compression sample. The following slip planes were identified: (102),(112), (111), (10T), (41T), (1 18), $(\overline{2} 1 \overline{3}),(\overline{3} 2 \overline{3}),(\overline{4} 15),(100)$, and $(010)$. Plastic deformation was usually less than $1 \%$; but in one case, deformation was over $13 \%$. Most samples taken to failure exhibited brittle fracture.

\footnotetext{
Work performed under the auspices of the U. S. Atomic Energy Commission.
} 


\section{Introduction}

The crystallographic aspects of metal deformation are now reasonably understood, although moat of the effort thus far has been directed towards metals with high gymmetry, auch as cubic and hexasonal. In faco-centered cubic metals, the alip plane in uevally the most denecly packed plane in the lattice, namely (111). This is alwo true of the hexaconal clono-pecked metals, where the basal plane (0001) is generally the dominant dip plane. In body-centered cubic lattices, slip may proceed on several phanes, all hrviog a high atomic density; however, the alip direction is almost always the closect-pecked direction in the slip plane.

The crystal structure of alphe plutonium is complex, with low symmetry. The structure is monoclinic, spece group (P21/m), with 16 atoms in the unit celk 1$)$. Conjectures on powible slip elernents are very speculative because of the complex structure. Attempts to chrracterize the deformation ayatems have been frustrated, no doubt, by the unavilability of hre crystals for experimental study. Early attempts to establich deformation planes in alpha phutoninsm have been directed towards (020). This plane has relatively hich atomic dentity and is the only ideally flat plane in the crystal structure.

Spriet $(2,3)$ has reported that $(020)$ is the dominant slip plane, based on studies of polycrystalline sumples at room iemperature. Bronizz and Tate(4), wing relatively anall crystalk, have reported that slip pianes near (114), (213), and (323) probibly are operative at room temperature. They state that no evidence has been found that (020) is a very important elip plane.

The purpose of this investigation has been to study the deformation elements of siphe plutonium at room temperature, and to identify these quantitatively by twoaurface analysis.

\section{Experimental Techniques}

Large crysts's of alpha plutonium were erown by the phase-transformation technique at $r$ es of $55 \mathrm{kbar}(5)$. Prismatic specimens were prepared by removing large $: . .$. by grinding. Surfaces were prepared metaliographically by auccessive grindin apring, and chemical polishing techniques previously reported(6). A typical specimen is shown in Figure 1 .

All of the plutonium had been purified by fused-salt electromefining(7). The total impurity content, exclesiye of americium, was about $300 \mathrm{ppm}$ by weight. The americium content, which was due to decay of $241 \mathrm{Pu}$, was about $200 \mathrm{ppm}$ at the time of experiments.

Crystallopraphic orientations were determinod by back-reflection Laue techniqued(6). At leset two surfaces of the deformation specimen were indexed; in many cabes, three or four surfaces were oriented (see Figure 1).

Deformation specimens were strained in compreation on an Instron testins machine. Cromhead displecement was 0.002 in. per min (nominal sunin nte $\sim 2 \%$ 
per min). The deformation markings then were photographed. Two-aurface analyis was used to determine the crystallographic planes of the deformation markings, with an accuracy of \pm 3 des.

\section{$\underline{\text { Results and Diecuesion }}$}

The load-displacement chancteriatics of the specimens are shown in Fizure 2. Six of the samples failed ahortly after deviating from a linear load-dieplacement relationship. Specimen J was subjected to a total strain of over $16 \%$ and was noticeably barrel-shaped after straining. Specimen F partially failed at about $320 \mathrm{lb}$.

From the data shown in Firure 2, nominal values of yield stress and elastic modulus were calculated (we Table 1). Yield stres was taken as the marked deviation from linearity of the kad-displecement curve. Nominal strains $\left(\Delta l / 1_{0}\right)$ and initial aress $\left(A_{0}\right)$ were uned in all calculations. Values of yield strewes ranged from 34,200 psi to 101,000 psi, whereas values of the elastic modulus ranged from $0.51 \times 106 \mathrm{pai}$ to $1.30 \times 106 \mathrm{pai}$.

Microphotographs of two aurfaces of Specimen E are shown in Fizure 3. The dominant slip plane was (112); however, a limited amount of slip was noted on the (010) plane.

Slip planes deternined by the two-surface analysis in this study, plus thone reported by Broniez and Tate(4), are shown in Figure 4. The planes given are within $\div 2$ deg of the two-aurface solution. The reaults are somewhat puzzling for a crystalline material. Each specimen tested revealed a different slip plane. The only phane duplicated was (112). In the two specimens where (010) was a result of two-aurface aralyais, crly a limited amount of plastic deformation was observed; only a few slip

Table I. Summary of Data and Reaults

\begin{tabular}{|c|c|c|c|c|c|c|}
\hline $\begin{array}{c}\text { Speci- } \\
\text { nien }\end{array}$ & $\begin{array}{l}\text { Compreacion } \\
\text { Direction }\end{array}$ & Sip Pane & $\begin{array}{l}\text { Nominal } \\
\text { Yield Strea } \\
\text { (P/A }- \text { poi) }\end{array}$ & $\begin{array}{l}\text { Nominal } \\
\text { Elastic } \\
\text { Modulus } \\
\text { (pai X 106) }\end{array}$ & $\begin{array}{c}\text { Area foo } \\
\text { (in.2) }\end{array}$ & $\begin{array}{c}\text { Length } 1_{0} \\
\text { (in.) }\end{array}$ \\
\hline $\begin{array}{l}\mathbf{A} \\
\mathbf{B} \\
\mathbf{C} \\
\mathbf{D} \\
\mathbf{E} \\
\mathbf{F} \\
\mathbf{G} \\
\mathbf{H} \\
\mathbf{I} \\
\mathbf{J} \\
\mathbf{K}\end{array}$ & 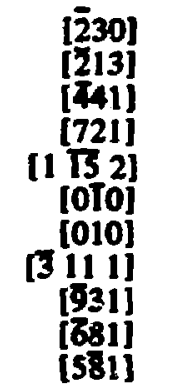 & $\begin{array}{c}(102) \\
(118) \\
(10 \%) \\
(111) \&(411) \\
(112) \&(010) \\
(112) \\
(323) \\
(213) \\
(100) \\
(415) \\
(010)\end{array}$ & $\begin{array}{r}93,000 \\
83,700 \\
101,000 \\
40,600 \\
65,300 \\
84,300 \\
50,000 \\
48,200 \\
56,500 \\
34,200 \\
36,900\end{array}$ & $\begin{array}{l}1 . \overline{05} \\
1.30 \\
0.78 \\
0.77 \\
1.18 \\
1.05 \\
0.68 \\
0.62 \\
0.61 \\
.0 .51\end{array}$ & $\begin{array}{r}0.0050 \\
.0105 \\
.0021 \\
.0016 \\
.0052 \\
.0038 \\
.0034 \\
.0028 \\
.0046 \\
.0038 \\
0.0049\end{array}$ & $\begin{array}{l}0.111 \\
.200 \\
.107 \\
.115 \\
.071 \\
.130 \\
.135 \\
.071 \\
.098 \\
.112 \\
0.005\end{array}$ \\
\hline
\end{tabular}


lines were observed and used in the analysis. The alip planes observed in this study were enerally within 10 des of the maximum shear plane ( 45 des to compresion axis) and covered a broad orientation spectrum in the $(010)$ standard projection of. plane poles (Figure 4).

It was a general practice to re-polish specimen aurfaces after straining and photofaphing. Twinning deformations were oberved in only one case; the extent of twinning was very limited and could not be projected by two-surface analysis. Therefore, in this study (at room temperature), twinning could not be said to be a major deformation element.

Other studies of deformation mechanisms in monoclinic structures usually have been limited to feologic materials. In these studies, slip has been oberved fenerally on only one plane(8). In the majority of cases, this plane has been (100), (010), or (001). The results of this study show many slip planes to be operntive, apparently depending on the crystallozmphic struin direction. One factor which may explain these perplexing results is the temperature at which the teats have been conducted: room temperature. Since the melting temperature of plutonium is $640^{\circ} \mathrm{C}, \mathrm{T}_{\mathrm{T}} \mathrm{m}$ is approximately $1 / 3$, a relatively high value. Generally in metal systems, the number of dip phnes increases as the temperature increases. Extending the experimental parameters to include lower and higher temperatures, and enlarging the room temperature studies to include a wider range of crystallographic strain directions, would be helpful in explaining the deformation elements operative in alpha plutonium.

\section{Acknowledgments}

The experimental work was accomplished at Argonne National Laboratory. The authors wish to express their gratitude to Dr. Merwyn Brodsky for his encouragement throughout this study. Thanks are also extended to Dr. James Rechtien for helpful discussions.

\section{References}

1. Zachariasen, W. H., and Ellinger, F. J. Chem. Phys., Vol. 27, No. 3, 1957, p. 81 L.

2. Spriet, B., "Mecanismes de Deformation du Plutonium Alpha," J. Nucl. Mater., Vol. 12, No, 2, 1964, p. 159-166.

3. Spriet, B., "Determenation du Plan de Glisement Majour dan le Plutonium Alpha," J. Nucl. Mater., Vol. 15, No. 1, 1965, p. 113-116.

4. Bronirz, S. E., and Tate, R. E., "Slip in Alpha Putonium," Proceedings of the Thind International Conference on Plutonium, The Institute of Metals, London, T965.

5. Liptai, R. G., and Friddle, R. J." "Hith Presure Crystal Growth of Alpha Phutonium," J. Cryst. Growth, Vol. 5, 1969, p. 216-218. 
6. Friddle, R. J, Liptai, R. G., Lloyd, L. T., and Odie, M. D., "Metallographic and X-Ray Studies of Alpha Plutonium," Advances in Metallorraphy, RFP-658, Dow Chemical Company, Rocky Flats Division, Golden, Colorado, 1966, pp. 185-194.

7. Blumenthal, B., and Brodaky, M. B., "Preparation of High-Purity Ptutonium," Plutonium - 1960, ed. E. Grison et al., Cleaver-Hume, London, 1961, p. 171.

8. Handin, J., "Strength and Ductility," Handbook of Physical Conatants, ed. S.P. Clark, Geological Society of America Nemoir 97, New York, 1966, p. 239-240. 


\section{Lint of Finures}

1. Deformation specimen ( 2 ). Single crystal of phutonium prepared by hich presare and temperature treatment(5), with back-reflection Lue pattem(6) of one of its surfacos. Tuneten radintion, $50 \mathrm{kV}, 20 \mathrm{~mA}, 3 \mathrm{~cm}$ specimen-to-film diatance, $1 \mathrm{~mm}$ collimator, $4 \mathrm{hr}$ expoaure.

2. Losd-displacement characteriatic of the deformatin specimens.

3. Microphotographs of two aurfaces on a Specimen $E$ after deformation. The dip plane is (112). Polarizod light (X50).

4. Slip planes in alpha plutonium determined by two-surface analyaix, shown on (010) standard projoction of plane poles. 

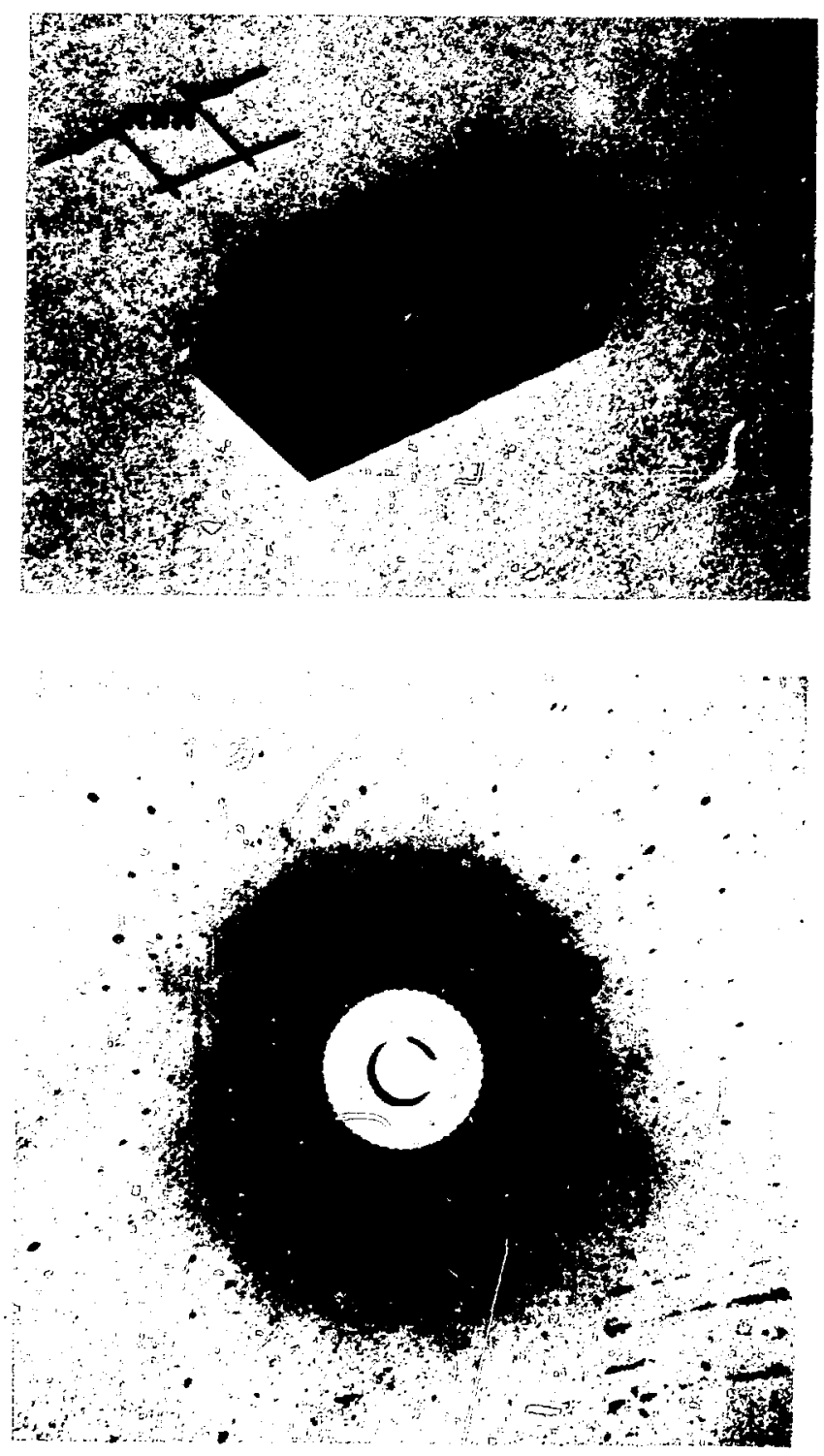


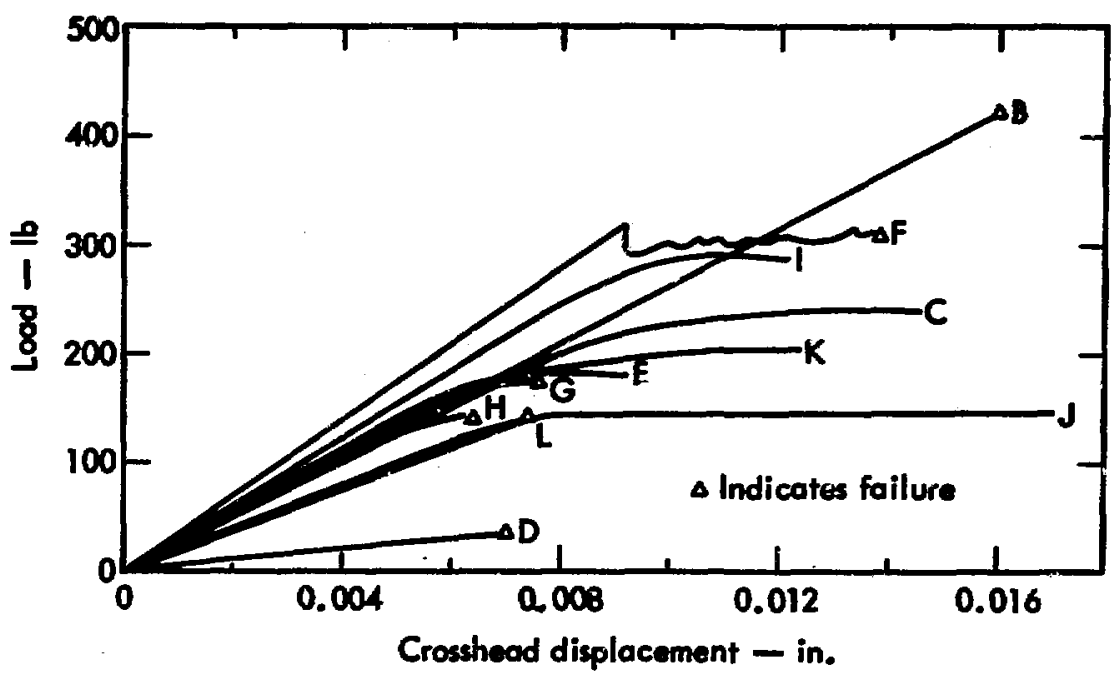

Liptai - Fig. 2 


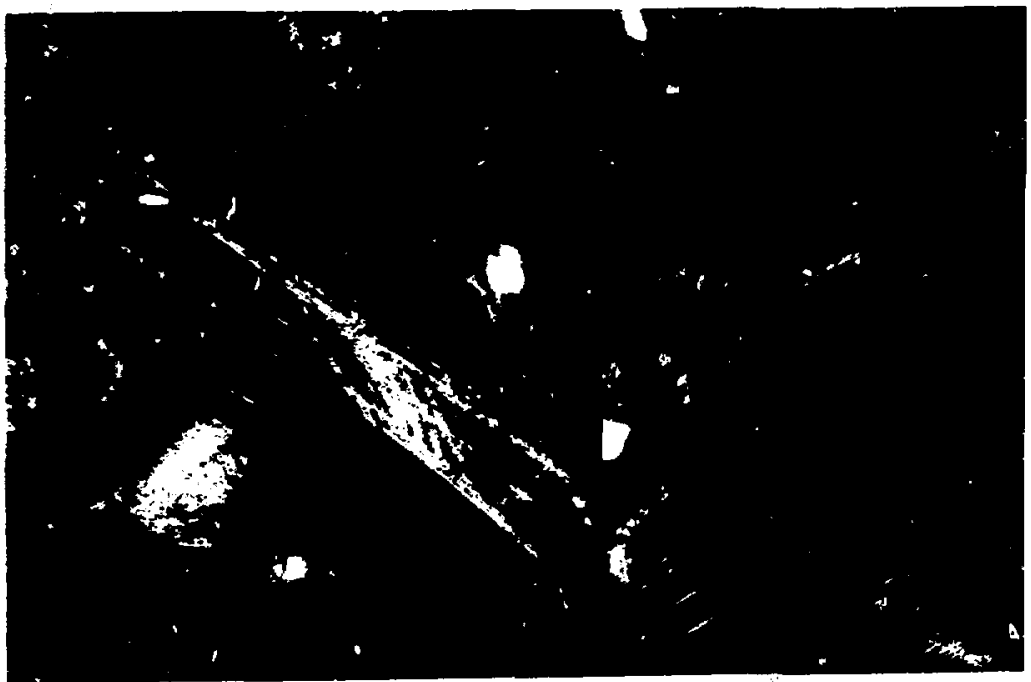

Liptni - Fig. 3 


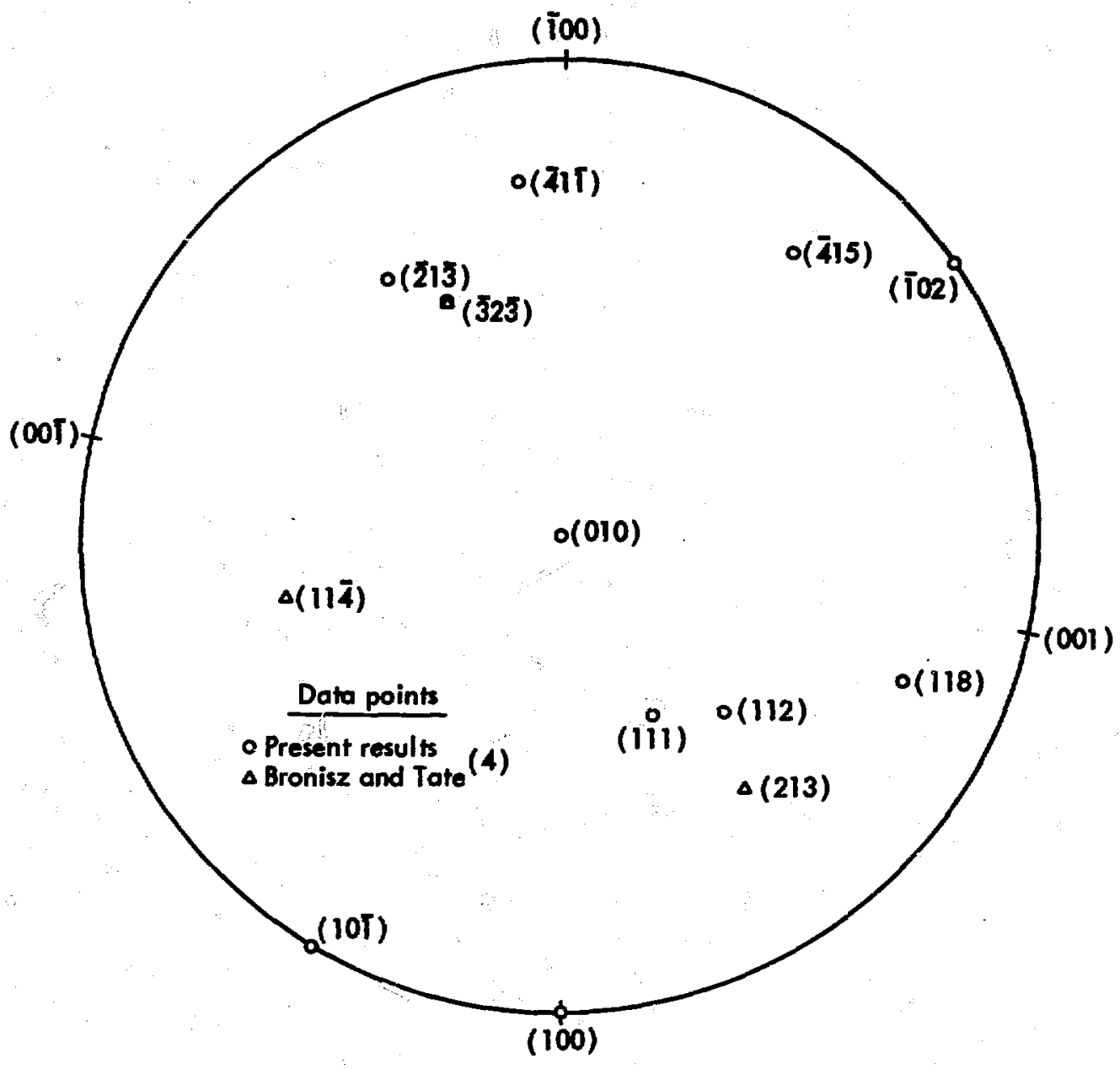

Liptai - Fig. 4 